\title{
Effect of Switching from Linagliptin to Teneligliptin Dipeptidyl Peptidase-4 Inhibitors in Older Patients with Type 2 Diabetes Mellitus
}

This article was published in the following Dove Press journal: Diabetes, Metabolic Syndrome and Obesity: Targets and Therapy

\author{
Eugene Han $\mathbb{D I}^{\prime}$ \\ Minyoung Lee ${ }^{2}$ \\ Yong-ho Lee $\mathbb{D}^{2-4}$ \\ Hye Soon Kim $\mathbb{D}^{1}$ \\ Byung-wan Lee $\mathbb{D D}^{2-4}$ \\ Bong-Soo $\mathrm{Cha}^{2-4}$ \\ Eun Seok Kang $\mathbb{D}^{2-4}$ \\ 'Division of Endocrinology and \\ Metabolism, Department of Internal \\ Medicine, Keimyung University School of \\ Medicine, Daegu, Republic of Korea; \\ ${ }^{2}$ Division of Endocrinology and \\ Metabolism, Department of Internal \\ Medicine, Yonsei University College of \\ Medicine, Seoul, Republic of Korea; \\ ${ }^{3}$ Institute of Endocrine Research, Yonsei \\ University College of Medicine, Seoul, \\ Republic of Korea; ${ }^{4}$ Severance Hospital \\ Diabetes Center, Yonsei University \\ College of Medicine, Seoul, Republic of \\ Korea
}

Introduction: Dipeptidyl peptidase-4 (DPP-4) inhibitors are widely prescribed for type 2 diabetes (T2D) and their glycemic control effects are well studied. However, information regarding the effects of switching DPP-4 inhibitors is limited, especially in older patients.

Research Design and Methods: We investigated whether switching from linagliptin to teneligliptin decreases blood glucose in older ( $\geq 65$ years) T2D patients. In total, 164 patients with T2D who switched from linagliptin to teneligliptin for $>12$ weeks were included and the primary outcome was glycemic changes.

Results: Switching from linagliptin to teneligliptin ameliorated fasting blood glucose (148.1 \pm 47.1 to $139.6 \pm 43.4 \mathrm{mg} / \mathrm{dL})$, glycated hemoglobin (HbA1c; $7.9 \pm 1.3$ to $7.5 \pm 1.2 \%$ ), and postprandial blood glucose $(224.8 \pm 77.4$ to $205.8 \pm 70.8 \mathrm{mg} / \mathrm{dL}$ ) levels (all $\mathrm{P}<0.05)$. Lowdensity lipoprotein cholesterol concentration was reduced while liver and kidney functions were maintained. Subgroup analysis showed that glucose control improved more in patients with uncontrolled hyperglycemia $(\mathrm{HbAlc}>8.0 \%)$ and chronic kidney disease (estimated glomerular filtration rate $<90 \mathrm{~mL} / \mathrm{min} / 1.73 \mathrm{~m}^{2}$ ). Multiple logistic analysis indicated higher baseline $\mathrm{HbAlc}$ was the strongest predictor of teneligliptin switching response. Conclusion: Switching from linagliptin to teneligliptin helps maintain kidney function and reduce blood glucose safely in older patients with T2D.

Keywords: dipeptidyl peptidase 4 inhibitor, linagliptin, teneligliptin, type 2 diabetes mellitus, older patients, chronic kidney disease

\section{Introduction}

Type 2 diabetes (T2D) has become a pandemic and with the aging population, its prevalence in older individuals is increasing widely. ${ }^{1}$ In Korea, the prevalence of T2D in older persons (over 65 years) is currently $29.8 \%$ and it has been projected that by 2060 , it will be $40.1 \%$ in this population. ${ }^{2}$ Additionally, T2D and its complications are an important cause of morbidity and mortality, leading to psychosocial economic burden. ${ }^{3}$

Dipeptidyl peptidase-4 (DPP-4) inhibitors are incretin-based drugs that increase active endogenous concentrations of glucagon-like peptide-1 (GLP-1), a gutderived hormone that stimulates insulin secretion and delays gastric emptying. ${ }^{4}$ DPP-4 inhibitors are associated with a low risk of hypoglycemia and body weight gain and have moderate efficacy in blood glucose control; thus, these drugs are one of the most commonly prescribed. Many clinical studies have shown that DPP-4 inhibitors are less likely to cause hypoglycemia than other agents such as
Correspondence: Eun Seok Kang Division of Endocrinology and Metabolism, Department of Interna Medicine, Yonsei University College of Medicine, 50-I, Yonsei-ro, Seodaemun-gu, Seoul 03722, Republic of Korea

Tel +82 222281938

Fax +8223936884

Email edgo@yuhs.ac 
sulfonylureas, which have similar potency. ${ }^{5}$ One of the major concerns in choosing antidiabetic medication for older patients with T2D is hypoglycemia. Considering their pharmacological action mechanism including glucose-dependent effects, DPP-4 inhibitors would be a good option for members of older populations with T2D.

Teneligliptin is a novel DPP-4 inhibitor and its chemical structure comprises five consecutive rings, a phenyl ring on the pyrazole, and an S2 extensive subsite, which magnifies its sensitivity and potency. ${ }^{6}$ Several studies have shown the clinical efficacy and safety of teneligliptin, both as a monotherapy and dual therapy in combination with other hypoglycemic drugs including metformin, sulfonylureas, and insulin. ${ }^{4,-10}$ In addition, teneligliptin can be used in patients with T2D who have renal impairment without the need for dose reduction. ${ }^{11}$

Another consideration in choosing anti-hyperglycemic agents for older patients with T2D is patient adherence and kidney function. Numerous medications are associated with poor compliance, especially in older individuals. ${ }^{12}$ To maintain the number of medications, switching those in the same class would be a useful strategy. Multiple DPP-4 inhibitors are now clinically available, wherein each has different chemical structure, inhibitory activity towards DPP-4, and tissue distribution. However, there is limited information regarding the difference in the efficacy among DPP-4 inhibitors. To address this important clinical question, we conducted an exploratory investigation to assess the effect of switching from linagliptin to teneligliptin in older patients with T2D.

\section{Experimental Section Methods}

In this retrospective study, subjects were identified by reviewing patient case notes in the electronic medical records at Severance Hospital, a tertiary university hospital in Korea and Dongsan Medical Center, a tertiary university hospital in Korea. We included 164 patients $\geq 65$ years old with a history of switching from linagliptin to teneligliptin for glycemic control. T2D was defined according to the International Classification of Diseases 10th revision. Only those who had not used teneligliptin in the preceding year were enrolled. Teneligliptin was used for at least 12 weeks.

Patients were excluded if they fulfilled any one of the following criteria: (1) kidney transplant or taking immunosuppressant agents; (2) intrinsic renal disease (nephritis or nephrotic syndrome); (3) acute renal failure due to septic shock, contrast agents, or drugs; (4) postrenal disease, (5) added or changed medications except teneligliptin; and (6) had missing baseline clinical or biochemical parameter data. The patients record was anonymized and de-identified prior to analysis. The daily dose of $5 \mathrm{mg}$ linagliptin to $20 \mathrm{mg}$ of teneligliptin was correspondence. The study protocol received ethical approval from the institutional review board at the Yonsei University College of Medicine (4-2016-0154) and Keimyung University School of Medicine (2017-11-034).

\section{Clinical and Laboratory Parameters}

We evaluated the effects of glucose parameters presented as fasting blood glucose (FBG), glycated hemoglobin (HbAlc), and postprandial blood glucose (PPBG) before and after switching from linagliptin to teneligliptin. The relationships between medication switching and lipid profile as well as renal function were also analyzed. Estimated glomerular filtration rates (eGFRs) were calculated using the Chronic Kidney Disease Epidemiology Collaboration equation. ${ }^{13}$ Clinical parameters of age, sex, height, weight, and duration of diabetes were recorded and the body mass index (BMI) was calculated using the following formula: $\mathrm{BMI}=$ body weight $(\mathrm{kg}) /$ height $\left(\mathrm{m}^{2}\right)$.

\section{Data Analysis}

The primary outcome was glycemic changes following the switch from linagliptin to teneligliptin. Subgroup analyses were stratified by baseline $\mathrm{HbAlc}(\leq 8.0 \%$ vs $>8.0 \%)$ according to the American Diabetes Association (ADA) recommendation for older patients, ${ }^{14}$ or eGFR $(\geq 90 \mathrm{~mL} /$ $\mathrm{min} / 1.73 \mathrm{~m}^{2}$ [chronic kidney disease, CKD stage 1], 60-89 $\mathrm{mL} / \mathrm{min} / 1.73 \mathrm{~m}^{2}$ [CKD stage 2], $<60 \mathrm{~mL} / \mathrm{min} /$ $1.73 \mathrm{~m}^{2}$ [CKD stage 3 or more]). Responders were defined as those exhibiting a $\geq 10 \%$ reduction in $\mathrm{HbAlc}$ values after 12 weeks of teneligliptin treatment. ${ }^{15}$

\section{Statistical Analysis}

The data are reported as means \pm standard deviation (SD), and the actual numbers of participants with the percentages are in parentheses. Simple comparisons of continuous variables within or between sub-groups were made using the Student's t-tests. Paired data measured at baseline and after switching linagliptin to teneligliptin were compared using paired t-tests. Because total cholesterol, triglyceride, high-density lipoprotein (HDL) cholesterol, and low-density lipoprotein (LDL) cholesterol values 
were not normally distributed, analyses were performed using log- and back-transformed data. Chi-square tests were used to examine the relationships between multiple variables. The relative factor for teneligliptin was obtained using multiple logistic regression and the benefit is reported as odds ratios (ORs) and 95\% confidence intervals (CIs). All statistical analyses were performed using the statistical package for the social sciences (SPSS) software program (SPSS version 25.0, IBM Corp, Armonk, NY, USA). For all tests, $\mathrm{P}<0.05$ was considered statistically significant.

\section{Results}

\section{Subject Clinical Characteristics}

Table 1 shows the baseline clinical characteristics of patients and 164 (69 males and 95 females) patients were recruited who had a mean age of $74.5 \pm 6.2$ years. The mean duration of T2D was $16.0 \pm 13.1$ years and mean $\mathrm{HbA1c}$ value was $7.9 \pm 1.3 \%$. The mean eGFR was $60.7 \pm$ $25.0 \mathrm{~mL} / \mathrm{min} / 1.73 \mathrm{~m}^{2}$ and the proportion of patients with CKD stage 1,2 , and $>3$ was $14.0 \%, 35.4 \%$, and $50.6 \%$, respectively. Furthermore, $70.1 \%$ of patients had hypertension that was relatively well controlled (mean systolic blood pressure, $129.3 \pm 16.4 \mathrm{mmHg}$, mean diastolic blood pressure, $69.2 \pm 10.6 \mathrm{mmHg}$ ) and $62.2 \%$ of the study population had a prior history of cardiovascular diseases. The anti-hyperglycemic drugs co-administered with DPP-4 inhibitors were metformin (60.4\%), sulfonylureas (48.2\%), and insulin (29.3\%). More than a quarter of these patients were using angiotensin-converting enzyme inhibitors or angiotensin receptor blockers.

\section{Effects of Switching Linagliptin to Teneligliptin on Hyperglycemia}

The glycemic parameters of patients were significantly ameliorated after switching from linagliptin to teneligliptin (FBG, from $148.1 \pm 47.1 \mathrm{mg} / \mathrm{dL}$ to $139.6 \pm 43.4 \mathrm{mg} / \mathrm{dL}, \mathrm{P}=0.041$; $\mathrm{HbA} 1 \mathrm{c}$, from $7.9 \pm 1.3 \%$ to $7.5 \pm 1.2 \%, \mathrm{P}<0.001$; and $\mathrm{PPBG}$, from $224.8 \pm 77.4 \mathrm{mg} / \mathrm{dL}$ to $205.8 \pm 70.8 \mathrm{mg} / \mathrm{dL}, \mathrm{P}=0.002$; Figure 1). Less than half of the study population (42.7\%) had difficulty in controlling T2D (baseline $\mathrm{HbA} 1 \mathrm{c} \geq 8.0 \%$ ). Both uncontrolled and controlled hyperglycemia groups showed improvement in glycemic parameters. However, patients with uncontrolled hyperglycemia showed significantly better responses than patients with controlled T2D did (FBG, from $160.0 \pm 60.1 \mathrm{mg} / \mathrm{dL}$ to $146.5 \pm 50.8 \mathrm{mg} / \mathrm{dL}, \mathrm{P}=0.085$, HbA1c, $9.1 \pm 1.1 \%$ to $8.2 \pm 1.3 \%, \mathrm{P}<0.001$; and PPBG, from $254.8 \pm$
Table I Baseline Characteristics of Study Population

\begin{tabular}{|c|c|}
\hline Age, years & $74.5 \pm 6.2(70.0-78.8)$ \\
\hline Male sex, N (\%) & $69(42.1)$ \\
\hline Duration of type 2 diabetes, years & $16.0 \pm 13.1(8.1-21.9)$ \\
\hline Body mass index, $\mathrm{kg} / \mathrm{m}^{2}$ & $25.2 \pm 3.5(23.0-27.0)$ \\
\hline Systolic blood pressure, $\mathrm{mmHg}$ & $129.3 \pm 16.4(119.0-140.0)$ \\
\hline Diastolic blood pressure, $\mathrm{mmHg}$ & $69.2 \pm 10.6(61.0-77.0)$ \\
\hline Fasting blood glucose, mg/dl & $147.8 \pm 46.6(\mid 17.0-163.0)$ \\
\hline $\mathrm{HbAlc} \%$ & $7.9 \pm 1.3(7.1-8.5)$ \\
\hline Postprandial blood glucose, $\mathrm{mg} / \mathrm{dl}$ & $225.8 \pm 78.1(167.0-276.3)$ \\
\hline BUN, mg/dl & $22.2 \pm 14.2(14.0-26.3)$ \\
\hline Creatinine, $\mathrm{mg} / \mathrm{dl}$ & I. $3 \pm$ I.I (0.8-I.4) \\
\hline eGFR, $\mathrm{mL} / \mathrm{min} / 1.73 \mathrm{~m}^{2}$ & $60.7 \pm 25.0(40.9-84.0)$ \\
\hline CKD stage I, N (\%) & $23(14.0)$ \\
\hline CKD stage $2, \mathrm{~N}(\%)$ & $58(35.4)$ \\
\hline CKD stage $3, \mathrm{~N}(\%)$ & $29(17.7)$ \\
\hline CKD stage $4, N(\%)$ & $36(22.0)$ \\
\hline CKD stage $5, \mathrm{~N}(\%)$ & $18(11.0)$ \\
\hline Albumin, mg/dL & $4.2 \pm 0.4(3.9-4.4)$ \\
\hline Total cholesterol, mg/dl & $153.8 \pm 36.7(\mid 28.0-178.0)$ \\
\hline Triglyceride, mg/dl & $143.4 \pm 72.6(89.3-180.9)$ \\
\hline HDL cholesterol, mg/dl & $44.0 \pm 14.1(35.6-50.0)$ \\
\hline LDL cholesterol, mg/dl & $83.7 \pm 29.6(105.9-84.0)$ \\
\hline AST, IU/L & $25.3 \pm 11.5(18.0-29.0)$ \\
\hline ALT, IU/L & $23.6 \pm 15.5(14.0-27.0)$ \\
\hline \multicolumn{2}{|l|}{ Comorbidities } \\
\hline Hypertension, N (\%) & II5 (70.I) \\
\hline Cardiovascular disease, N (\%) & $102(62.2)$ \\
\hline \multicolumn{2}{|l|}{ Medications, N (\%) } \\
\hline Metformin & $99(60.4)$ \\
\hline SU & $79(48.2)$ \\
\hline TZD & $10(6.1)$ \\
\hline Insulin & $48(29.3)$ \\
\hline Lipid lowering agents & $110(67.1)$ \\
\hline ACE inhibitor/ARB & $72(43.9)$ \\
\hline $\mathrm{CCB}$ & $56(34.1)$ \\
\hline Diuretics & $43(26.2)$ \\
\hline
\end{tabular}

Note: Data are presented as $N(\%)$ or mean \pm SD (interquartile range). Abbreviations: HbAlc, glycated hemoglobin Alc; BUN, blood urea nitrogen; eGFR, estimated glomerular filtration rate; CKD, chronic kidney disease; HDL cholesterol, high-density lipoprotein cholesterol; LDL, low-density lipoprotein cholesterol; AST, aspartate transaminase; ALT, alanine transferase; SU, sulfonylurea; TZD, thiazolidinedione; ACE inhibitor, angiotensin-converting enzyme inhibitor; ARB, angiotensin II receptor blocker; CCB, calcium channel blocker.

$62.8 \mathrm{mg} / \mathrm{dL}$ to $226.6 \pm 71.6 \mathrm{mg} / \mathrm{dL}, \mathrm{P}=0.010$; Supplementary Figure 1).

A total of 141 patients had impaired renal function $\left(\mathrm{eGFR}<90 \mathrm{~mL} / \mathrm{min} / 1.73 \mathrm{~m}^{2}\right)$ and more than a half of the patients were diagnosed with CKD stage $\geq 3$. Hyperglycemia was attenuated both in patients with normal and impaired renal function (Table 2). However, a significant decline in blood glucose was found only in 


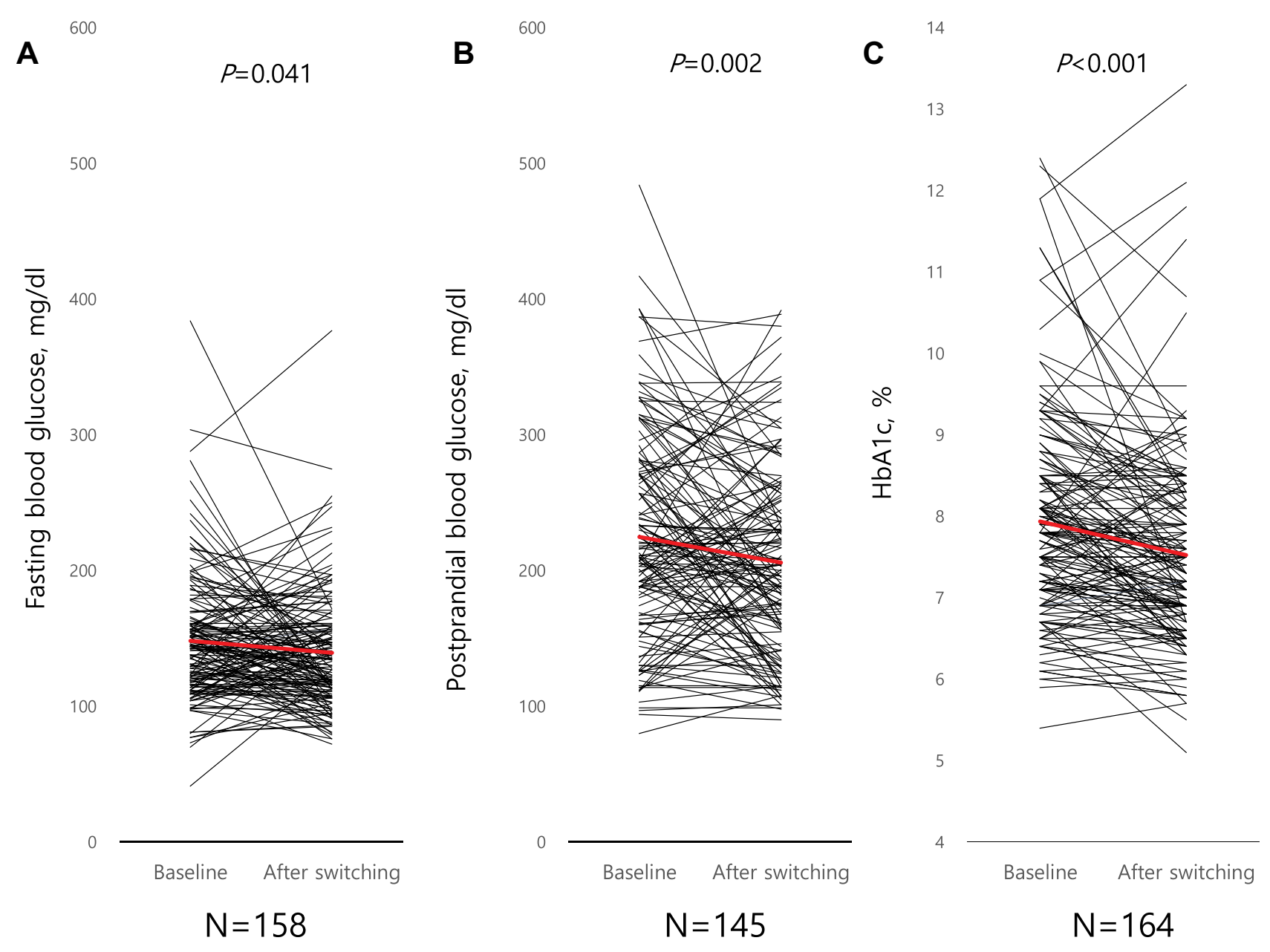

Figure I Changes in glycemic parameters after switching to teneligliptin. (A) Fasting blood glucose, (B) postprandial blood glucose, and (C) glycated hemoglobin Alc $(\mathrm{HbAlc})$. Red line indicates trend line.

patients with impaired renal function. In $58(35.4 \%)$ patients with $\mathrm{CKD}$ stage 2, FBG was decreased from $154.9 \pm 51.4 \mathrm{mg} / \mathrm{dL}$ to $137.6 \pm 28.1 \mathrm{mg} / \mathrm{dL}(\mathrm{P}=0.013)$, HbA1c was decreased from $7.7 \pm 1.1 \%$ to $7.2 \pm 0.9 \%(\mathrm{P}<$ 0.001 ), and PPBG was decreased from $214.6 \pm 85.1 \mathrm{mg} /$ $\mathrm{dL}$ to $188.3 \pm 68.0 \mathrm{mg} / \mathrm{dL}(\mathrm{P}=0.019)$. Furthermore, 83 $(50.6 \%)$ patients with impaired renal function (CKD stage $\geq 3$ ) experienced significant decline in HbA1c (from $8.2 \pm$ $1.5 \%$ to $7.7 \pm 0.9 \%, \mathrm{P}=0.002)$ while 44 (26.8\%) patients experienced $>10 \%$ decline in $\mathrm{HbA} 1 \mathrm{c}$ and were identified as the teneligliptin response group.

There were no significant differences in geodemographic parameters at baseline (Table 3). However, the teneligliptin response group had a higher baseline blood glucose, lower triglyceride level, and a higher proportion of insulin users than the non-response group did. Multivariable analysis showed that a higher baseline $\mathrm{HbA1c}$ was associated with a better response to teneligliptin $(\mathrm{OR}=2.44,95 \%$ CI $1.63-3.67$, $\mathrm{P}<0.001)$. However, the use of lipid-lowering agents and a higher triglyceride level was linked to reduced response to teneligliptin (OR $=0.40,95 \% \mathrm{CI} 0.17-0.97, \mathrm{P}=0.042$ for lipid-lowering agent users, and $\mathrm{OR}=0.34,95 \% \mathrm{CI} 0.14-0.82$, $\mathrm{P}=0.016$ for triglyceride, Table 4 ).

\section{Effects of Switching Linagliptin to Teneligliptin on Metabolic Parameters}

At enrollment, $67.1 \%$ of the patients used lipid-lowering agents. Serum LDL cholesterol levels were significantly decreased from $85.6 \pm 30.2 \mathrm{mg} / \mathrm{dL}$ to $78.9 \pm 32.7 \mathrm{mg} / \mathrm{dL}$ $(\mathrm{P}=0.004)$, and there were no significant changes in total cholesterol, triglyceride, and HDL cholesterol levels after switching from linagliptin to teneligliptin. The renal function and liver enzymes were conserved (Table 5).

\section{Discussion}

The major finding of this study is that switching from linagliptin to teneligliptin may facilitate the control of hyperglycemia in older patients with T2D. Specifically, 
Table 2 Changes in Glycemic Parameters by Chronic Kidney Disease Stages

\begin{tabular}{|c|c|c|c|c|}
\hline Parameters & Before Switching & After Switching & $\Delta$ & $P$ value \\
\hline \multicolumn{5}{|l|}{ CKD stage I $(\mathrm{N}=23)$} \\
\hline Fasting blood glucose, mg/dl & $|3| .0 \pm 26.2$ & $138.3 \pm 36.9$ & $7.3 \pm 48.6$ & 0.482 \\
\hline $\mathrm{HbAlc}, \%$ & $7.7 \pm 0.8$ & $7.5 \pm 0.9$ & $-0.2 \pm 0.8$ & 0.244 \\
\hline Postprandial blood glucose, $\mathrm{mg} / \mathrm{dl}$ & $225.2 \pm 83.6$ & $203.2 \pm 66.4$ & $-22.0 \pm 68.2$ & 0.156 \\
\hline \multicolumn{5}{|l|}{ CKD stage $2(\mathrm{~N}=58)$} \\
\hline Fasting blood glucose, $\mathrm{mg} / \mathrm{dl}$ & $154.9 \pm 51.4$ & $137.6 \pm 38.1$ & $-17.3 \pm 50.0$ & 0.013 \\
\hline $\mathrm{HbAlc} \%$ & $7.7 \pm 1.1$ & $7.3 \pm 0.9$ & $-0.5 \pm 0.7$ & $<0.001$ \\
\hline Postprandial blood glucose, $\mathrm{mg} / \mathrm{dl}$ & $214.6 \pm 85.1$ & $188.3 \pm 68.0$ & $-26.2 \pm 77.4$ & 0.019 \\
\hline \multicolumn{5}{|l|}{ CKD stage 3- $(\mathrm{N}=83)$} \\
\hline Fasting blood glucose, $\mathrm{mg} / \mathrm{dl}$ & $147.8 \pm 47.5$ & $14 \mid .3 \pm 48.4$ & $-6.6 \pm 53.6$ & 0.275 \\
\hline HbAlc, \% & $8.2 \pm 1.5$ & $7.7 \pm 1.4$ & $-0.4 \pm 1.2$ & 0.002 \\
\hline Postprandial blood glucose, $\mathrm{mg} / \mathrm{dl}$ & $231.8 \pm 70.0$ & $218.8 \pm 72.0$ & $-13.0 \pm 72.4$ & 0.129 \\
\hline
\end{tabular}

Note: Data are presented as $\mathrm{N}(\%)$ or mean $\pm \mathrm{SD}$.

Abbreviations: HbAlc, glycated hemoglobin Alc; CKD, chronic kidney disease.

Table 3 Comparison of Response to Teneligliptin Switching

\begin{tabular}{|c|c|c|c|}
\hline & Non-Responder $(\mathbf{N}=\mid \mathbf{2 0})$ & Responder $(\mathrm{N}=44)$ & $P$ value \\
\hline Age, years & $74.4 \pm 6.1$ & $74.9 \pm 6.6$ & 0.627 \\
\hline Male sex, N (\%) & $46(38.3)$ & $23(52.3)$ & 0.109 \\
\hline Duration of type 2 diabetes, years & $15.3 \pm 13.7$ & $18.0 \pm 11.1$ & 0.245 \\
\hline Body mass index, $\mathrm{kg} / \mathrm{m}^{2}$ & $25.3 \pm 3.6$ & $25.0 \pm 3.1$ & 0.661 \\
\hline Fasting blood glucose, $\mathrm{mg} / \mathrm{dl}$, baseline & $142.9 \pm 41.0$ & $160.8 \pm 57.5$ & 0.064 \\
\hline Fasting blood glucose, $\mathrm{mg} / \mathrm{dl}$, after switching & $141.2 \pm 37.9$ & $135.0 \pm 56.0^{* *}$ & 0.428 \\
\hline HbAlc, \%, baseline & $7.6 \pm 1.1$ & $8.9 \pm 1.4$ & $<0.001$ \\
\hline $\mathrm{HbAlc}$ \%, after switching & $7.6 \pm 1.3$ & $7.3 \pm 1.0 * *$ & 0.118 \\
\hline Postprandial blood glucose, $\mathrm{mg} / \mathrm{dl}$, baseline & $220.3 \pm 76.2$ & $240.3 \pm 82.2$ & 0.163 \\
\hline Postprandial blood glucose, $\mathrm{mg} / \mathrm{dl}$, after switching & $199.2 \pm 68.0 * *$ & $222.8 \pm 74.7$ & 0.089 \\
\hline eGFR, $\mathrm{mL} / \mathrm{min} / 1.73 \mathrm{~m}^{2}$, baseline & $64.7 \pm 24.5$ & $59.4 \pm 29.1$ & 0.173 \\
\hline eGFR, $\mathrm{mL} / \mathrm{min} / 1.73 \mathrm{~m}^{2}$, after switching & $60.1 \pm 22.2$ & $54.4 \pm 28.8$ & 0.242 \\
\hline Total cholesterol, mg/dl, baseline* & $161.2 \pm 39.0$ & $145.5 \pm 30.5$ & 0.122 \\
\hline Total cholesterol, mg/dl, after switching* & $152.8 \pm 37.0 * *$ & $152.6 \pm 48.9$ & 0.696 \\
\hline Triglyceride, mg/dl, baseline* & $159.0 \pm 75.3$ & $120.8 \pm 61.5$ & 0.007 \\
\hline Triglyceride, $\mathrm{mg} / \mathrm{dl}$, after switching* & $154.7 \pm 74.0$ & $126.7 \pm 53.3$ & 0.017 \\
\hline HDL cholesterol, mg/dl, baseline* & $43.0 \pm 10.9$ & $45.6 \pm 17.1$ & 0.789 \\
\hline HDL cholesterol, mg/dl, after switching* & $42.7 \pm 10.0$ & $46.3 \pm 20.1$ & 0.672 \\
\hline LDL cholesterol, mg/dl, baseline* & $87.4 \pm 32.6$ & $80.6 \pm 23.1$ & 0.740 \\
\hline LDL cholesterol, mg/dl, after switching* & $78.4 \pm 31.3^{* *}$ & $80.4 \pm 36.5$ & 0.914 \\
\hline \multicolumn{4}{|l|}{ Medications, N (\%) } \\
\hline Metformin & $77(64.2)$ & $22(50.0)$ & 0.100 \\
\hline SU & $54(45.0)$ & $25(56.8)$ & 0.180 \\
\hline TZD & $6(5.0)$ & $4(9.1)$ & 0.332 \\
\hline Insulin & $30(25.0)$ & $18(40.9)$ & 0.047 \\
\hline Statin & $85(70.8)$ & $25(56.8)$ & 0.091 \\
\hline
\end{tabular}

Notes: Data are presented as $N(\%)$ or mean \pm SD. *Log transformed. $* * P<0.05$ compared with baseline.

Abbreviations: HbAlc, glycated hemoglobin Alc; BUN, blood urea nitrogen; eGFR, estimated glomerular filtration rate; CKD, chronic kidney disease; HDL cholesterol, high-density lipoprotein cholesterol; LDL, low-density lipoprotein cholesterol; AST, aspartate transaminase; ALT, alanine transferase; SU, sulfonylurea; TZD, thiazolidinedione; ACE inhibitor, angiotensin-converting enzyme inhibitor; ARB, angiotensin II receptor blocker; CCB, calcium channel blocker. 
Table 4 Multiple Regression Analysis to Determine Variables Associated Responders of Switching to Teneligliptin

\begin{tabular}{|l|l|l|l|}
\hline & OR & $\mathbf{9 5 \%} \mathbf{C l}$ & P value \\
\hline Age, year & 1.00 & $0.93-\mathrm{I} .07$ & 0.947 \\
Sex, male & $\mathrm{I} .10$ & $0.46-2.62$ & 0.832 \\
Body mass index, $\mathrm{kg} / \mathrm{m}^{2}$ & 0.99 & $0.87-\mathrm{I} . \mathrm{I3}$ & 0.927 \\
Duration of type 2 diabetes, year & 0.88 & $0.97-\mathrm{I} .03$ & 0.880 \\
Baseline HbAIc, \% & 2.44 & $1.62-3.67$ & $<0.00 \mathrm{I}$ \\
Triglyceride, baseline, $\mathrm{mg} / \mathrm{d} \mathrm{I}^{*}$ & 0.34 & $0.14-0.82$ & 0.016 \\
LDL cholesterol, $\mathrm{mg} / \mathrm{d} \mathrm{I}^{*}$ & 0.95 & $0.30-3.10$ & 0.954 \\
CKD stage 3 or more & 0.97 & $0.4 \mathrm{I}-2.59$ & 0.929 \\
Lipid lowering agent use & 0.40 & $0.17-0.97$ & 0.042 \\
Insulin use & 0.99 & $0.34-2.99$ & 0.989 \\
\hline
\end{tabular}

Note: *log-transformed.

Abbreviations: OR, odds ratio; $95 \% \mathrm{Cl}, 95 \%$ confidence interval; $\mathrm{HbAlc}$, glycated hemoglobin AIc; LDL cholesterol, low-density lipoprotein cholesterol; CKD, chronic kidney disease.

switching to teneligliptin reduced hyperglycemia in patients with impaired renal function while maintaining their eGFR, indicating the renoprotective effect of teneligliptin. In addition, the effects were greater in patients with uncontrolled than in those with controlled hyperglycemia independent of other contributing factors including age, sex, duration of T2D, and insulin use. Guidelines of both the Korean Diabetes Association and ADA recommend the combination or supplementation of other classes of anti-hyperglycemic agents to achieve glycemic targets. ${ }^{16,17}$ In addition to achieving the glycemic goal, maintaining glucose levels without inducing hypoglycemia is important and, therefore, guidelines emphasize an individualized glycemic target considering life expectancy, complications of $\mathrm{T} 2 \mathrm{D}$, and advanced age.

Those factors are more prevalent in the older population and older patients are more vulnerable to hypoglycemia. ${ }^{18} \mathrm{In}$ addition, an increase in the number of medications reduces patient adherence and supplementation with other hypoglycemic agent increases the possibility of drug interactions and side effects as well as medical costs. Consequently, switching agents from the same class of antihyperglycemic agents would be a reasonable and relatively safe strategy, and would provide an alternative therapeutic option. In this study, we provide clinical evidence to show that switching agents in the same drug class could be a viable option before considering adding drugs from other classes. Moreover, our data showed a more potent glucose-lowering effect in patients with uncontrolled hyperglycemia than in those with controlled hyperglycemia.

The difference in binding site and affinity of the receptor site is possibly associated with the efficacy of switching from linagliptin to teneligliptin in blood glucose control. DPP-4 inhibitors are categorized according to their binding site and teneligliptin is classified as a class 3 agent, whereas linagliptin is characterized as class $2 .{ }^{19}$ Teneligliptin has a unique J-shape structure formed by five rings directly connected and the loss of entropy is small at the binding site. Teneligliptin is a peptide mimetic and the carbonyl group forms a hydrogen bond at the binding site, strengthening the binding interaction. ${ }^{20}$ In addition, the anchor lock domain ([1-phenylpyrazol-5-yl] piperazine moiety) makes teneligliptin to bind more tightly to the DPP-4 enzyme than other gliptins ands well as enhances the selectivity of the binding. ${ }^{20}$ The long endurance and strong binding affinity of teneligliptin to the DPP-4 enzyme makes it more potent, and it further decreases blood glucose levels when patients switched to this agent. Teneligliptin, which is also a class 3 DPP-4 inhibitor, increased activated GLP-1 levels more than sitagliptin did, as reported in a Japanese pilot study. ${ }^{21}$ Moreover, recent studies demonstrated that teneligliptin rescues endothelial cell viability through the ERK5/KLF2 signaling pathway. ${ }^{22,23}$ However, it would still be necessary to investigate whether the differences in binding modes

Table 5 Changes in Metabolic Parameters After Switching to Teneligliptin

\begin{tabular}{|l|l|l|l|l|}
\hline Parameters & Baseline & After Switching & $\Delta$ & $P$ value \\
\hline eGFR, mL/min/I.73m & $60.1 \pm 24.9$ & $58.6 \pm 24.1$ & $-1.5 \pm 11.7$ & 0.109 \\
Total cholesterol, mg/dL* & $156.9 \pm 37.4$ & $152.7 \pm 40.5$ & $-4.2 \pm 41.8$ & 0.128 \\
Triglycerides, mg/dL* & $148.8 \pm 73.7$ & $147.3 \pm 70.0$ & $-1.5 \pm 62.1$ & 0.837 \\
HDL cholesterol, mg/d* & $43.7 \pm 12.8$ & $43.7 \pm 13.5$ & $0.1 \pm 13.1$ & 0.951 \\
LDL cholesterol, mg/d** & $85.6 \pm 30.2$ & $78.9 \pm 32.7$ & $-6.6 \pm 34.3$ & 0.004 \\
AST, IU/L* & $25.4 \pm 11.6$ & $25.5 \pm 13.9$ & $0.1 \pm 11.8$ & 0.475 \\
ALT, IU/L* & $23.7 \pm 15.7$ & $22.1 \pm 14.6$ & $-1.6 \pm 12.9$ & 0.065 \\
\hline
\end{tabular}

Notes: Data are presented mean \pm SD. *log-transformed.

Abbreviations: eGFR, estimated glomerular filtration rate; HDL cholesterol, high-density lipoprotein cholesterol, LDL cholesterol; low-density lipoprotein cholesterol; AST, aspartate transaminase; ALT, alanine transferase. 
between teneligliptin and other DPP-4 inhibitors are clinically meaningful.

In glycemic control, DPP-4 inhibitors generally decrease HbAlc levels $(0.5-1.0 \%)$ and the efficacy among DPP-4 inhibitors is similar. ${ }^{4,24-26}$ However, the effect of switching between DPP-4 inhibitors has been scantly studied and studies have reported conflicting results according to the type of DPP-4 inhibitor. A retrospective study conducted in the UK demonstrated that the changes in HbAlc after switching to alogliptin were insignificant. ${ }^{27}$ However, a recent prospective study showed a positive result in switching to teneligliptin. ${ }^{28}$ The additional $0.4 \%$ reduction in $\mathrm{HbA} 1 \mathrm{c}$ levels observed in the present study was comparable to that previously reported, ${ }^{28}$ although the baseline characteristics of the patients were different from those of our study. Our results showed that the effect of switching to teneligliptin was favorable in older patients with impaired renal function and long T2D duration, suggesting the efficacy was comparable to that in a younger population and those with normal kidney function. More head-to-head, comparative trials are needed to confirm the glycemic efficacy in changing DPP-4 inhibitors.

In addition to glucose-lowering effects, numerous studies have suggested that DPP-4 inhibitors have a pleiotropic effect on other organs including the kidney and blood vessels. $^{29-31}$ The potential protective effects or inhibitory actions of these agents against the progression of diabetic kidney disease are mediated through anti-inflammatory, antioxidative, and anti-fibrotic activities. ${ }^{31-34}$ Among DPP4 inhibitors, the renoprotective effect of linagliptin has been well studied and dose reduction is not required in patients with CKD. ${ }^{33-35}$ Both teneligliptin and linagliptin have higher lipophilicity and greater distribution in the kidney than that of other DPP4 inhibitors. ${ }^{36}$ Additionally, a pilot study showed a more significant reduction in DPP-4 activity of both teneligliptin and linagliptin than that of other DPP-4 inhibitors, and failed to demonstrate any distinction between teneligliptin and linagliptin. ${ }^{37}$ Our results did not show any statistical significance in changes of eGFR after patients switched to teneligliptin; however, a significant reduction in $\mathrm{HbA1c}$ occurred only in patients with impaired renal function. This observation suggests the comparable renoprotective effect of linagliptin, indicating that switching to teneligliptin might be beneficial for T2D patients with CKD.

Our results are in accordance with a previous metaanalysis showing that baseline HbAlc is the strongest predictor of responses to DPP-4 inhibitors. ${ }^{24,25}$ However, we unexpectedly discovered the lipid-lowering use and found that higher triglyceride concentrations are associated with a lower response following switching to teneligliptin. Although we did not find any association between teneligliptin response and BMI, other studies showed that an insulin-resistant state could reduce responses to DPP-4 inhibitors. In a cohort study in the UK, obesity $(\geq 30 \mathrm{~kg} /$ $\left.\mathrm{m}^{2} \mathrm{BMI}\right)$ and increased triglyceride markedly reduced glycemic response and durability of DPP-4 inhibitor therapy. ${ }^{38}$ A Japanese study reported similar results that the average triglyceride level was an independent factor contributing to the efficacy of DPP-4 inhibitor in obese patients. $^{39}$ Lipotoxicity disrupts cell-to-cell communication in incretin-sensitive beta cells, impairing GLP-1 response, thus, altering insulin secretion. ${ }^{40}$ In addition, fatty acid mediates downregulation of the expression of connexin 36, an integral membrane protein cluster at gap junction domains of beta-cell membranes. ${ }^{41}$ The experimental data suggest that alterations of this signaling impair beta-cells connectivity.

Our study has a few limitations that are worth mentioning. First, because it was a retrospective investigation, some confounders might have influenced glycemic control other than anti-hyperglycemic medications. Although the patients were prescribed the same number of medications, they exhibited hyperglycemia; thus, there might be some attempt to improve this condition. Second, we did not include a control group. Further head-to-head studies are needed to elucidate the difference in glycemic control among DPP-4 inhibitors. Additionally, we did not investigate the outcome of switching from teneligliptin to linagliptin. Third, medication compliance was not fully considered in the present study. Because this was not a prospective study, we could not assess adherence to prescribed medications. The study data were based on the proposition that all the prescribed medications were administered to the patients.

In conclusion, our findings demonstrate that switching from linagliptin to teneligliptin in older patients with T2D ameliorated blood glucose levels and preserved kidney function. This suggests that switching DPP-4 inhibitors, especially to teneligliptin, could be a therapeutic option to control hyperglycemia in difficult-to-treat T2D. However, further randomized trials are needed to quantify this beneficial effect in switching to teneligliptin compared to other DPP4 inhibitors and control groups. 


\section{Abbreviations}

ADA, American Diabetes Association; BMI, body mass index; CKD, chronic kidney disease; DPP-4 inhibitor, dipeptidyl peptidase-4 inhibitor; eGFR, estimated glomerular filtration rate; GLP-1, glucagon-like peptide-1; HbA1c, glycated hemoglobin A1c; HDL cholesterol, high-density lipoprotein cholesterol; LDL cholesterol, low-density lipoprotein cholesterol; OR, T2D, type 2 diabetes, SD, standard deviation; odds ratio; 95\% CI, 95\% confidence interval.

\section{Author Contributions}

All authors made a significant contribution to the work reported, whether that is in the conception, study design, execution, acquisition of data, analysis and interpretation, or in all these areas; took part in drafting, revising or critically reviewing the article; gave final approval of the version to be published; have agreed on the journal to which the article has been submitted; and agree to be accountable for all aspects of the work.

\section{Funding}

Sponsorship for this study was funded by the Handok Inc, Seoul, Korea, and by the Severance Hospital Research Fund for Clinical excellence (SHRC, C-2020-0016). The funders had no role in study design, data collection and analysis, decision to publish, or preparation of the manuscript.

\section{Disclosure}

All authors state that they have no conflicts of interest and no competing financial interests.

\section{References}

1. Danaei G, Finucane MM, Lu Y, et al. National, regional, and global trends in fasting plasma glucose and diabetes prevalence since 1980: systematic analysis of health examination surveys and epidemiological studies with 370 country-years and 2.7 million participants. Lancet. 2011;378(9785):31-40.

2. Kim BY, Won JC, Lee JH, et al. Diabetes fact sheets in Korea, 2018: an appraisal of current status. Diabetes Metab J. 2019;43(4):487-494.

3. Schott G, Martinez YV, Ediriweera de Silva RE, et al. Effectiveness and safety of dipeptidyl peptidase 4 inhibitors in the management of type 2 diabetes in older adults: a systematic review and development of recommendations to reduce inappropriate prescribing. $B M C$ Geriatr. 2017;17(Suppl 1):226.

4. Kim Y, Kang ES, Jang HC, et al. Teneligliptin versus sitagliptin in Korean patients with type 2 diabetes inadequately controlled with metformin and glimepiride: a randomized, double-blind, non-inferiority trial. Diabetes Obes Metab. 2019;21(3):631-639.

5. Lukashevich V, Del Prato S, Araga M, Kothny W. Efficacy and safety of vildagliptin in patients with type 2 diabetes mellitus inadequately controlled with dual combination of metformin and sulphonylurea. Diabetes Obes Metab. 2014;16(5):403-409.
6. Kishimoto M. Teneligliptin: a DPP-4 inhibitor for the treatment of type 2 diabetes. Diabetes Metab Syndr Obes. 2013;6:187-195.

7. Hong S, Park CY, Han KA, et al. Efficacy and safety of teneligliptin, a novel dipeptidyl peptidase-4 inhibitor, in Korean patients with type 2 diabetes mellitus: a 24-week multicentre, randomized, double-blind, placebo-controlled Phase III trial. Diabetes Obes Metab. 2016;18(5):528-532.

8. Bryson A, Jennings PE, Deak L, Paveliu FS, Lawson M. The efficacy and safety of teneligliptin added to ongoing metformin monotherapy in patients with type 2 diabetes: a randomized study with open label extension. Expert Opin Pharmacother. 2016;17 (10):1309-1316.

9. Kadowaki T, Kondo K. Efficacy and safety of teneligliptin added to glimepiride in Japanese patients with type 2 diabetes mellitus: a randomized, double-blind, placebo-controlled study with an open-label, long-term extension. Diabetes Obes Metab. 2014;16(5):418-425.

10. Kadowaki T, Kondo K, Sasaki N, et al. Efficacy and safety of teneligliptin add-on to insulin monotherapy in Japanese patients with type 2 diabetes mellitus: a 16-week, randomized, double-blind, placebo-controlled trial with an open-label period. Expert Opin Pharmacother. 2017;18(13):1291-1300.

11. Sharma SK, Panneerselvam A, Singh KP, Parmar G, Gadge P, Swami OC. Teneligliptin in management of type 2 diabetes mellitus. Diabetes Metab Syndr Obes. 2016;9:251-260.

12. Monane M, Bohn RL, Gurwitz JH, Glynn RJ, Levin R, Avorn J. The effects of initial drug choice and comorbidity on antihypertensive therapy compliance: results from a population-based study in the elderly. Am J Hypertens. 1997;10(7 Pt 1):697-704.

13. Levey AS, Stevens LA, Schmid $\mathrm{CH}$, et al. A new equation to estimate glomerular filtration rate. Ann Intern Med. 2009;150 (9):604-612.

14. American Diabetes A. 12. Older adults: Standards of medical care in diabetes-2020. Diabetes Care. 2020;43(Suppl 1):S152-S162.

15. Han E, Park HS, Kwon O, et al. A genetic variant in GLP1R is associated with response to DPP-4 inhibitors in patients with type 2 diabetes. Medicine (Baltimore). 2016;95(44):e5155.

16. Kim MK, Ko SH, Kim BY, et al. 2019 clinical practice guidelines for Type 2 diabetes mellitus in Korea. Diabetes Metab J. 2019;43(4):398-406.

17. American Diabetes A. 9. Pharmacologic approaches to glycemic treatment: standards of medical care in diabetes-2020. Diabetes Care. 2020;43(Suppl 1):S98-S110.

18. Wang J, Geiss LS, Williams DE, Gregg EW. Trends in emergency department visit rates for hypoglycemia and hyperglycemic crisis among adults with diabetes, United States, 2006-2011. PLoS One. 2015;10(8): $\mathrm{e} 0134917$.

19. Nabeno M, Akahoshi F, Kishida H, et al. A comparative study of the binding modes of recently launched dipeptidyl peptidase IV inhibitors in the active site. Biochem Biophys Res Commun. 2013;434(2):191-196.

20. Yoshida T, Akahoshi F, Sakashita H, et al. Discovery and preclinical profile of teneligliptin (3-[(2S,4S)-4-[4-(3-methyl-1-phenyl-1Hpyrazol-5-yl)piperazin-1-yl]pyrrolidin-2-y lcarbonyl]thiazolidine): a highly potent, selective, long-lasting and orally active dipeptidyl peptidase IV inhibitor for the treatment of type 2 diabetes. Bioorg Med Chem. 2012;20(19):5705-5719.

21. Kurozumi A, Okada Y, Sugai K, Torimoto K, Tanaka Y. Comparison of the effects of Teneligliptin and Sitagliptin, Two Dipeptidyl Peptidase 4 Inhibitors with different half-lives, on glucose fluctuation and glucagon-like peptide-1 in Type 2 diabetes mellitus. $J$ UOEH. 2018;40(1):1-9.

22. Zhang Z, Jin X, Yang C, Li Y. Teneligliptin protects against hypoxia/ reoxygenation-induced endothelial cell injury. Biomed Pharmacother. 2019; 109:468-474.

23. Lei Zhang WY, Kongab X, Zhang B. Teneligliptin protects against ischemia/reperfusion-induced endothelial permeability in vivo and in vitro. $R S C A d v$. 2020;10:3765. 
24. Esposito K, Chiodini P, Capuano A, Maiorino MI, Bellastella G, Giugliano D. Baseline glycemic parameters predict the hemoglobin A1c response to DPP-4 inhibitors: meta-regression analysis of 78 randomized controlled trials with 20,053 patients. Endocrine. 2014;46(1):43-51.

25. Esposito K, Chiodini P, Maiorino MI, et al. A nomogram to estimate the $\mathrm{HbA} 1 \mathrm{c}$ response to different DPP-4 inhibitors in type 2 diabetes: a systematic review and meta-analysis of 98 trials with 24163 patients. BMJ Open. 2015;5(2):e005892.

26. Choe EY, Cho Y, Choi Y, et al. The effect of DPP-4 inhibitors on metabolic parameters in patients with Type 2 diabetes. Diabetes Metab J. 2014;38(3):211-219.

27. Strain WD, McEwan P, Howitt H, Meadowcroft S. Retrospective database analysis evaluating the clinical outcomes of changing treatment of people with Type 2 Diabetes Mellitus (T2DM) from other DPP-4 inhibitor therapy to alogliptin in a primary care setting. Diabetes Ther. 2019;10(4):1499-1507.

28. Kim HJ, Kim YS, Lee CB, et al. Efficacy and safety of switching to teneligliptin in patients with Type 2 diabetes inadequately controlled with dipeptidyl peptidase-4 inhibitors: a 12-week interim report. Diabetes Ther. 2019;10(4):1271-1282.

29. Son JW, Kim S. Dipeptidyl peptidase 4 inhibitors and the risk of cardiovascular disease in patients with Type 2 diabetes: a tale of three studies. Diabetes Metab J. 2015;39(5):373-383.

30. Rhee SY, Kim YS. The role of advanced glycation end products in diabetic vascular complications. Diabetes Metab J. 2018.

31. Kim MJ, Kim NY, Jung YA, et al. Evogliptin, a Dipeptidyl Peptidase-4 inhibitor, attenuates renal fibrosis caused by unilateral ureteral obstruction in mice. Diabetes Metab J. 2020;44(1):186-192.

32. Gangadharan Komala M, Gross S, Zaky A, Pollock C, Panchapakesan U. Saxagliptin reduces renal tubulointerstitial inflammation, hypertrophy and fibrosis in diabetes. Nephrology (Carlton). 2016;21(5):423-431.

33. Kanasaki K, Shi S, Kanasaki M, et al. Linagliptin-mediated DPP-4 inhibition ameliorates kidney fibrosis in streptozotocin-induced diabetic mice by inhibiting endothelial-to-mesenchymal transition in a therapeutic regimen. Diabetes. 2014;63(6):2120-2131.
34. Groop PH, Cooper ME, Perkovic V, Emser A, Woerle HJ, von Eynatten M. Linagliptin lowers albuminuria on top of recommended standard treatment in patients with type 2 diabetes and renal dysfunction. Diabetes Care. 2013;36(11):3460-3468.

35. Groop PH, Cooper ME, Perkovic V, et al. Linagliptin and its effects on hyperglycaemia and albuminuria in patients with type 2 diabetes and renal dysfunction: the randomized MARLINA-T2D trial. Diabetes Obes Metab. 2017;19(11):1610-1619.

36. Nakamaru Y, Akahoshi F, Iijima H, Hisanaga N, Kume T. Tissue distribution of teneligliptin in rats and comparisons with data reported for other dipeptidyl peptidase-4 inhibitors. Biopharm Drug Dispos. 2016;37(3):142-155.

37. Kitada M, Ogura Y, Nitta K, et al. Effect of switching to teneligliptin from other dipeptidyl peptidase-4 inhibitors on glucose control and renoprotection in type 2 diabetes patients with diabetic kidney disease. J Diabetes Investig. 2019;10(3):706-713.

38. Dennis JM, Shields BM, Hill AV, et al. Precision medicine in Type 2 diabetes: clinical markers of insulin resistance are associated with altered short- and long-term glycemic response to DPP-4 inhibitor therapy. Diabetes Care. 2018;41(4):705-712.

39. Shimoda M, Miyoshi-Takai M, Irie S, et al. Inadequate triglyceride management worsens the durability of dipeptidyl peptidase- 4 inhibitor in subjects with Type 2 diabetes mellitus. $J$ Diabetes Res. 2017;2017:5856475.

40. Hodson DJ, Mitchell RK, Bellomo EA, et al. Lipotoxicity disrupts incretin-regulated human beta cell connectivity. J Clin Invest. 2013;123(10):4182-4194.

41. Cigliola V, Chellakudam V, Arabieter W, Meda P. Connexins and beta-cell functions. Diabetes Res Clin Pract. 2013;99(3):250-259.

Diabetes, Metabolic Syndrome and Obesity: Targets and Therapy

Dovepress

\section{Publish your work in this journal}

Diabetes, Metabolic Syndrome and Obesity: Targets and Therapy is an international, peer-reviewed open-access journal committed to the rapid publication of the latest laboratory and clinical findings in the fields of diabetes, metabolic syndrome and obesity research. Original research, review, case reports, hypothesis formation, expert opinion and commentaries are all considered for publication. The manuscript management system is completely online and includes a very quick and fair peer-review system, which is all easy to use. Visit http://www.dovepress.com/testimonials.php to read real quotes from published authors. 